\title{
Association of orthodontic treatment needs and oral health-related quality of life
}

This article was published in the following Dove Press journal:

Patient Preference and Adherence

20 March 2015

Number of times this article has been viewed

\author{
Tatiana Saito Paiva \\ Marcia Andre \\ Department of Surgery, Prosthesis, \\ and Maxillofacial Traumatology, \\ University of Sao Paulo Dentistry \\ School, Sao Paulo, Brazil
}

\section{Dear editor}

We have read with great interest the recent paper by Hassan et al ${ }^{1}$ published in Patient Preference and Adherence. Quality of life is an important consideration in children with malocclusion due to the impacts in social life, especially at school. ${ }^{2}$ In this paper, Hassan et al ${ }^{1}$ highlighted the impact of malocclusion on quality of life, using an oral health-related quality of life (OHRQoL) scale in 120 children.

Measuring quality of life is complex due to the lack of consensus about what it really means; but in an academic setting, it is a tool commonly used to allow comparisons and evaluation of interventions. ${ }^{3}$ Previous clinical studies in orthodontics evaluated the quality of life of patients using several tools with the aim of measuring health care. ${ }^{3,4}$

This study has strengths. First, the authors have used two examiners calibrated for analysis of the dental health component using the index of orthodontic treatment needs, which gives reliability to the results. The second strength of this study is that it is the first study to use the Michigan OHRQoL scale to assess the association between OHRQoL and index of orthodontic treatment needs; also, in the present study, children with no/little need, children with borderline need, and children who need treatment were included. However, despite important results and widespread discussion, this study presents some limitations. The original Michigan OHRQoL scale was designed to investigate the effects of early childhood caries on children's OHRQoL, and is usually applicable to younger children. ${ }^{5}$ But in this study, patients up to 15 years old were included. Another important consideration is that the study could be performed including other settings to ensure generalization to Saudi children. Finally, the authors highlighted methodological accuracy used in the translation of questionnaires from English to Arabic; however, no validation study was performed, and this lack of construct validity may limit the interpretation of results. These questions, however, do not take away the main relevant messages raised in this interesting paper by Hassan et al. ${ }^{1}$

\section{Disclosure}

The authors report no conflicts of interest in this communication.

\section{References}

1. Hassan AH, Hassan MH, Linjawi AI. Association of orthodontic treatment needs and oral healthrelated quality of life in Saudi children seeking orthodontic treatment. Patient Prefer Adherence. 2014; 8:1571-1579.

2. de Oliveira CM, Sheiham A. Orthodontic treatment and its impact in oral health-related quality of life in Brazilian adolescents. J Orthod. 2004;31(1):20-27. 
3. Feu D, Quintão CC, Miguel JA. Quality of life instruments and their role in orthodontics. Dental Press J Orthod. 2010;15(6):61-70. [Portuguese].

4. Abreu LG, Lages EM, Abreu MH, Pereira LJ, Paiva SM. Preadolescent's oral health-related quality of life during the first month of fixed orthodontic appliance therapy. J Orthod. 2013;40(3):218-224.
5. Filstrup SL, Briskie D, da Fonseca M, Lawrence L, Wandera A, Inglehart MR. Early childhood caries and quality of life: child and parent perspectives. Pediatr Dent. 2003;25(5):431-440. 


\section{Authors' reply}

Ali H Hassan'

Mona HA Hassan ${ }^{2,3}$

Amal I Linjawi'

'Department of Orthodontics, ${ }^{2}$ Department of Dental Public Health, Faculty of Dentistry, King Abdulaziz University, Jeddah, Kingdom of Saudi Arabia; ${ }^{3}$ Department of Biostatistics, High Institute of Public Health, Alexandria University, Alexandria, Egypt

Correspondence: Ali H Hassan

Department of Orthodontics, Faculty of Dentistry, King Abdulaziz University, Jeddah, Kingdom of Saudi Arabia

Email aakbr@kau.edu.sa

\section{Dear editor}

In response to the interesting comments raised by Paiva and Andre about our recent paper titled "Association of orthodontic treatment needs and oral health-related quality of life in Saudi children seeking orthodontic treatment", ${ }^{1}$ we would like to clarify the following.

Paiva and Andre criticized the use of the original Michigan oral health-related quality of life (OHRQoL) scales on an older age group, which was up to 15 years, as the original scales were designed to investigate the effects of early childhood caries on children's OHRQoL in younger children. ${ }^{2}$ We would like to emphasize that the Michigan OHRQoL scales were used previously on a sample of adolescents/young adults with cleft lip/palate under 25 years of age. ${ }^{3}$
Also, we would like to clarify that we did a proper translation process in which scales were translated from English to Arabic language by experts in both languages. The questionnaires were translated first by a bilingual expert from English to Arabic. The resulting versions were then translated back to English by another bilingual expert who was blinded to the original questionnaires in English. The translated scales were then corrected and culturally adapted with the help of the experts to eliminate any difference in the meaning between the original questionnaire and the back-translated one. Validity of the scales was assessed by correlation of the scales with the index of orthodontic treatment needs and also by correlation between parent and child forms, and this was explained in the study.

\section{Disclosure}

The authors report no conflicts of interest in this communication.

\section{References}

1. Hassan AH, Hassan MH, Linjawi AI. Association of orthodontic treatment needs and oral health-related quality of life in Saudi children seeking orthodontic treatment. Patient Prefer Adherence. 2014;8:1571-1579.

2. Filstrup SL, Briskie D, da Fonseca M, Lawrence L, Wandera A, Inglehart MR. Early childhood caries and quality of life: child and parent perspectives. Pediatr Dent. 2003;25(5):431-440.

3. Munz SM, Edwards SP, Inglehart MR. Oral health-related quality of life, and satisfaction with treatment and treatment outcomes of adolescents young adults with cleft lip/palate: an exploration. Int J Oral Maxillofac Surg. 2011;40:790-796.

\section{Publish your work in this journal}

Patient Preference and Adherence is an international, peer-reviewed, open access journal that focuses on the growing importance of patient preference and adherence throughout the therapeutic continuum. Patient satisfaction, acceptability, quality of life, compliance, persistence and their role in developing new therapeutic modalities and compounds to optimize clinical outcomes for existing disease states are major areas of interest for the journal. This journal has been accepted for indexing on PubMed Central The manuscript management system is completely online and includes a very quick and fair peer-review system, which is all easy to use. Visit http://www. dovepress.com/testimonials.php to read real quotes from published authors. 